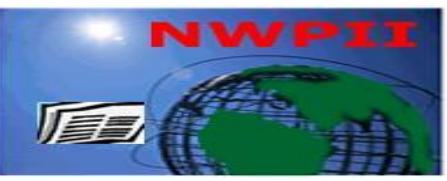

American Journal of Biomedical Sciences

ISSN: 1937-9080

nwpii.com/ajbms

\title{
Evaluation of Toxicological Profile of Ibuprofen in Wistar Albino Rats
}

\author{
Jonah Sydney Aprioku ${ }^{1 *}$, Lucky Legbosi Nwidu $^{2}$, Cecilia Nwadiuto Amadi ${ }^{3}$
}

${ }^{1}$ Department of Pharmacology, Faculty of Basic Medical Sciences, University of Port Harcourt, Port Harcourt, Nigeria

${ }^{2}$ Department of Pharmacology and Toxicology, Faculty of Pharmacy, Niger Delta University, Wilberforce Island,

Yenagoa, Bayelsa State, Nigeria.

${ }^{3}$ Department of Clinical Pharmacy and Management, Faculty of Pharmaceutical Sciences, University of Port Harcourt,

Port Harcourt, Nigeria

*Corresponding Author

Jonah Sydney Aprioku

Department of Pharmacology

Faculty of Basic Medical Sciences

University of Port Harcourt

Port Harcourt, Nigeria

Phone: +234(0) 8035082379

Email: sydaprio@yahoo.com

Received: 26 February 2014; | Revised: 16 March 2014; | Accepted: 22 March 2014

\begin{abstract}
Ibuprofen is an effective, cheap, and frequently used non-steroidal anti-inflammatory drug. The present study investigated the dose- and time-dependent effects of ibuprofen on hepatic, renal, and hematological functions in rats. Groups of rats $(\mathrm{n}=6)$ were given ibuprofen $\left(20,40 \mathrm{mgkg}^{-1} \mathrm{day}^{-1}\right)$ for 7,14 or 28 days; or vehicle (control), orally. Blood samples were obtained, and hematological indices and biochemical markers of hepatic and renal functions were measured. Ibuprofen significantly increased, $\mathrm{P}<$ 0.001 serum alkaline phosphatase level at all doses and durations of exposure. Serum uric acid level was dose- and time-dependently decreased by ibuprofen, but alanine transaminase was increased, $\mathrm{P}<0.05$ by ibuprofen, only at $40 \mathrm{mgkg}^{-1}$ and following subchronic (28 days) exposure. In addition, at $40 \mathrm{mgkg}^{-1}$, ibuprofen increased creatinine and urea levels at all durations of exposure; but at $20 \mathrm{mgkg}^{-1}$, creatinine and urea were increased only in rats that were exposed for 28 days. Furthermore, subchronic exposure of 40 $\mathrm{mgkg}^{-1}$ ibuprofen increased, $\mathrm{P}<0.01 \mathrm{WBC}$ count, but it caused no significant effect on WBC at the lower durations of exposure and dose. Also, while RBC and hematocrit were not affected, ibuprofen significantly, $\mathrm{P}<0.01, \mathrm{P}<0.001$ decreased platelet counts in all treated rats except those that were exposed for 7 days. The implication of this research is that chronic use of ibuprofen could affect hepatic, renal and hematological functions in the rat; and duration of exposure may promote ibuprofen toxicity relative to dose.
\end{abstract}

Keywords: Aminotransferases, ibuprofen, platelets, renal toxicity, subchronic 


\section{Introduction}

Ibuprofen, a propionic acid derivative, is an example of the non-steroidal anti-inflammatory drugs (NSAIDs), which are among the most frequently prescribed medications worldwide $[1,2]$. Ibuprofen is one of the most commonly used NSAIDs for the relief of fever, pains and inflammatory conditions. The drug is reported to be better and preferred for joint and muscle pain than most other analgesics and has been used by patients with arthritis for years [3]. The mechanism of action of ibuprofen, like other NSAIDs, has been established to be via inhibition of cyclooxygenase (COX) enzyme activity [4]. Inhibition of COX enzyme by NSAIDs results in prevention of the synthesis of prostaglandins which mediate vital physiological functions, including gastric cytoprotection, maintenance of renal blood flow, and platelet activation [5].

Although, NSAIDs are generally considered to have high safety profiles, the frequent and widespread use of ibuprofen and other NSAIDs is likely to increase the prevalence of their adverse effects. Ibuprofen and other NSAIDs are commonly associated with gastrointestinal (GI) toxicity [6,7]. In addition, NSAIDs have been shown in previous studies to alter renal function $[8,9]$. However, most of such reports are on high dose levels of the agents (> clinical doses) and existing data on ibuprofen-mediated renal toxicity in relation to duration of exposure is not exhaustive. Furthermore, NSAIDs are known to have antiplatelet activities [10], however, the antiplatelet effects of ibuprofen in relation to dose and duration of exposure is not fully established. Importantly, ibuprofen is an over-the-counter NSAID, with the consequence of an increase in its usage and toxicological potentials. We hypothesize that prolong exposure of clinical dose levels of ibuprofen would increase its adverse effects on biological systems. Herein, we investigated the effects of acute and subchronic exposure of clinical and double clinical dose equivalents of ibuprofen on hepatic, renal, and hematological functions in rats.

\section{Materials and methods}

\section{Materials}

Ibuprofen $\left(\right.$ Tabufen $^{\mathrm{R}}$ ) tablets (Fidson Pharm Ltd, Nigeria) was purchased from the Pharmacy Unit of the University of Port Harcourt Teaching Hospital, Port Harcourt, Nigeria. The drug was powdered and mixed with distilled water in a glass mortar and administered as aqueous suspension by oral gavage. The drug was continuously agitated during administration in order to deliver the drug homogeneously to the animals.

\section{Animals}

Male Wistar rats weighing between 210-220 $\mathrm{g}$, obtained from the Animal House of the Department of Pharmacology, University of Port Harcourt, were used for the study. The animals were fed with standard rodent chow (Topfeeds Ltd, Sapele, Nigeria) and allowed free access to tap water ad libitum. They were maintained at a room temperature of $28.0 \pm 2.0^{\circ} \mathrm{C}$ under natural lighting condition and handled in accordance with international guidelines for Care and Use of Laboratory Animals as promulgated by the Canadian Council of Animal Care [11].

\section{Experimental design}

The rats were divided into 7 groups containing 6 animals each. The first, second and third groups were given standard therapeutic dose equivalent of ibuprofen [12]: $20 \mathrm{mgkg}^{-1}$ daily (in two divided doses) for 7,14 and 28 days, respectively. The fourth, fifth and sixth groups were given $40 \mathrm{mgkg}^{-1}$ of ibuprofen daily (in two divided doses) for 7, 14 and 28 days, respectively. The seventh group served as control and was given distilled water daily for 28 days. At the end of each administration, the animals were anesthetized with deep diethylether and blood samples were collected separately into clean specimen bottles and EDTA bottles for biochemical and hematological analyses, respectively.

\section{Biochemical analysis}

Blood samples in specimen bottles were centrifuged for $15 \mathrm{~min}$ at $3,000 \mathrm{rpm}$ and clear 
sera were separated from the cells and stored at $-80^{\circ} \mathrm{C}$. Serum was assayed for alkaline phosphatase (ALP) using the phenolphthalein method [13]; acid phosphatase (ACP) using the colorimetric method [14]; urea using the UreaseBerthelot method [15]; creatinine using the alkaline picrate method [16]; protein using the biuret method [17]; uric acid using the enzymatic colorimetric method [18]; and total cholesterol using the enzymatic endpoint method [19]. Serum aspartate transaminase (AST) and alanine transaminase (ALT) levels were also measured according to the method described by Reitman and Frankel [20].

\section{Hematological analysis}

Whole blood collected into EDTA bottle was assayed for hematocrit or packed cell volume (PCV). White blood cell (WBC), red blood cell (RBC) and platelet counts were also determined using an autoanalizer.

\section{Statistical analysis}

Data are expressed as mean \pm SEM. Comparisons between control values and experimental values were performed with oneway analysis of variance (ANOVA), followed by Dunnett comparison test. Statistical significance was set at $\mathrm{P} \leq 0.05$.

\section{Results}

\section{Biochemical parameters}

Serum alkaline phosphatase (ALP) levels in all ibuprofen exposed rats were significantly, $\mathrm{P}<$ 0.001 increased, when compared to control rats (Table 1). In addition, while acid phosphatase (ACP) levels were significantly, $\mathrm{P}<0.001$ increased in rats that received $40 \mathrm{mgkg}^{-1}$ ibuprofen for 14 and 28 days, ACP levels in all $20 \mathrm{mgkg}^{-1}$ ibuprofen treated rats, as well as those that received $40 \mathrm{mgkg}^{-1}$ ibuprofen for 7 days were not significantly different from control (Table 1). Average serum level of alanine transaminase (ALT) in rats that received $40 \mathrm{mgkg}^{-1}$ ibuprofen for 28 days was significantly, $\mathrm{P}<0.05$ increased, while there were no changes in ALT levels in all other treated rats, when compared to control rats (Table 2).

Table 1: Serum levels of phosphatase enzymes following different dose and time administration of ibuprofen in rats

\begin{tabular}{lllllll}
\hline Dose & \multicolumn{3}{c}{ ALP $\left(\mathrm{IU} \mathrm{L}^{-1}\right)$} & \multicolumn{3}{c}{ ACP $\left(\mathrm{IU} \mathrm{L}^{-1}\right)$} \\
\hline \multirow{2}{*}{ Control } & 7 Days & 14 Days & 28 Days & 7 Days & 14 Days & 28 Days \\
$20 \mathrm{mg} / \mathrm{kg}$ & $81.00 \pm 6.38^{*}$ & $82.75 \pm 3.30^{*}$ & $80.25 \pm 5.79^{*}$ & $3.25 \pm 1.89$ & $4.00 \pm 0.82$ & $5.00 \pm 2.16$ \\
$40 \mathrm{mg} / \mathrm{kg}$ & $87.75 \pm 7.00^{*}$ & $108.80 \pm 18.87 *$ & $95.25 \pm 10.56^{*}$ & $5.00 \pm 1.16$ & $10.75 \pm 2.63 *$ & $10.50 \pm 2.65^{*}$
\end{tabular}

Data expressed as mean \pm SEM. * Significant at $\mathrm{P}<0.001$. ALP- alkaline phosphatase; ACP- acid phosphatase.

Furthermore, while serum creatinine levels in 7 days treated rats were not affected, it was elevated, $\mathrm{P}<0.001$ in rats that received ibuprofen for 28 days, when compared to control (Table 3 ). In the 14 days treated rats, creatinine level was significantly, $\mathrm{P}<0.001$ increased in those that received $40 \mathrm{mgkg}^{-1}$ ibuprofen, while it was not affected in those that received $20 \mathrm{mgkg}^{-1}$ ibuprofen (Table 3). In addition, there were no changes in serum levels of urea in all $20 \mathrm{mgkg}^{-1}$ ibuprofen treated rats, but it was significantly, $\mathrm{P}$ $<0.01, \mathrm{P}<0.001$ and time-dependently increased in $40 \mathrm{mgkg}^{-1}$ ibuprofen treated rats, compared to control (Table 3). Furthermore, when compared to control, serum uric acid levels obtained in ibuprofen exposed rats were significantly lower 
at all doses and durations of exposure. The effects of ibuprofen on uric acid were also dose- and time-dependent (Table 5). There were no significant $(\mathrm{P}>0.05)$ changes in serum AST, protein and cholesterol levels in ibuprofen exposed rats, when compared to their corresponding levels that were obtained in control rats (Table 2, Table 4).

Table 2: Serum levels of transaminase enzymes following different dose and time administration of ibuprofen in rats

\begin{tabular}{lllllll}
\hline Dose & \multicolumn{3}{c}{ AST $\left(\mathrm{IU} \mathrm{L}^{-1}\right)$} & \multicolumn{3}{c}{ ALT (IU L $\left.{ }^{-1}\right)$} \\
\hline & 7 Days & 14 Days & 28 Days & 7 Days & 14 Days & 28 Days \\
Control & $22.75 \pm 2.06$ & $22.75 \pm 2.06$ & $22.75 \pm 2.06$ & $10.50 \pm 0.65$ & $10.50 \pm 0.65$ & $10.50 \pm 0.65$ \\
$20 \mathrm{mg} / \mathrm{kg}$ & $25.00 \pm 2.31$ & $24.25 \pm 4.86$ & $26.25 \pm 5.62$ & $13.00 \pm 5.29$ & $11.50 \pm 4.20$ & $16.00 \pm 1.41$ \\
& & & & & & \\
$40 \mathrm{mg} / \mathrm{kg}$ & $27.50 \pm 1.73$ & $27.25 \pm 2.22$ & $28.25 \pm 1.50$ & $13.25 \pm 4.72$ & $15.50 \pm 6.14$ & $18.50 \pm 1.73^{*}$
\end{tabular}

Data expressed as mean \pm SEM. * Significant at $\mathrm{P}<0.05$. AST- aspartate transaminase; ALT- alanine transaminase.

Table 3: Serum levels of creatinine and urea following different dose and time administration of ibuprofen in rats

Dose Creatinine $\left(\mu \mathrm{mol} \mathrm{L}^{-1}\right) \quad$ Urea $\left(\mathrm{mmol} \mathrm{L}^{-1}\right)$

\begin{tabular}{lllllll}
\hline & 7 Days & 14 Days & 28 Days & 7 Days & 14 Days & 28 Days \\
Control & $35.00 \pm 4.76$ & $35.00 \pm 4.76$ & $35.00 \pm 4.76$ & $4.75 \pm 0.29$ & $4.75 \pm 0.29$ & $4.75 \pm 0.29$ \\
$20 \mathrm{mg} / \mathrm{kg}$ & $33.00 \pm 3.56$ & $47.00 \pm 3.46$ & $81.75 \pm 6.70 * *$ & $5.35 \pm 0.53$ & $5.50 \pm 0.49$ & $6.03 \pm 0.45$ \\
$40 \mathrm{mg} / \mathrm{kg}$ & $38.50 \pm 2.52$ & $79.75 \pm 10.37 * *$ & $93.00 \pm 11.34 * *$ & $6.65 \pm 0.65 *$ & $7.23 \pm 1.49 * *$ & $8.23 \pm 0.32 * *$
\end{tabular}

Data expressed as mean \pm SEM. * Significant at $\mathrm{P}<0.01 ; * *$ Significant at $\mathrm{P}<0.001$.

Table 4: Serum levels of total protein and cholesterol following different dose and time administration of ibuprofen in rats

\begin{tabular}{|c|c|c|c|c|c|c|}
\hline \multirow[t]{2}{*}{ Dose } & \multicolumn{3}{|c|}{ Total protein $\left(\mathrm{g} \mathrm{L}^{-1}\right)$} & \multicolumn{3}{|c|}{ Total cholesterol $\left(\mathrm{mmol} \mathrm{L}^{-1}\right)$} \\
\hline & 7 Days & 14 Days & 28 Days & 7 Days & 14 Days & 28 Days \\
\hline Control & $59.00 \pm 5.77$ & $59.00 \pm 5.77$ & $59.00 \pm 5.77$ & $1.08 \pm 0.13$ & $1.08 \pm 0.13$ & $1.08 \pm 0.13$ \\
\hline $20 \mathrm{mg} / \mathrm{kg}$ & $57.50 \pm 3.00$ & $57.00 \pm 3.83$ & $57.75 \pm 2.63$ & $1.33 \pm 0.30$ & $1.30 \pm 0.18$ & $1.10 \pm 0.29$ \\
\hline $40 \mathrm{mg} / \mathrm{kg}$ & $61.00 \pm 9.31$ & $57.50 \pm 2.52$ & $55.00 \pm 3.46$ & $1.07 \pm 0.22$ & $1.18 \pm 0.21$ & $4.15 \pm 5.90$ \\
\hline
\end{tabular}

Data expressed as mean \pm SEM. 
Table 5: Serum levels of uric acid following different dose and time administration of ibuprofen in rats

\section{Dose Uric acid $\left(\mathrm{mmol} \mathrm{L}^{-1}\right)$}

\begin{tabular}{llll}
\hline & 7 Days & 14 Days & 28 Days \\
Control & $0.46 \pm 0.24$ & $0.46 \pm 0.24$ & $0.46 \pm 0.24$ \\
$20 \mathrm{mg} / \mathrm{kg}$ & $0.19 \pm 0.12 *$ & $0.15 \pm 0.00 * *$ & $0.18 \pm 0.10 * *$ \\
$40 \mathrm{mg} / \mathrm{kg}$ & $0.09 \pm 0.04 * * *$ & $0.07 \pm 0.00 * * *$ & $0.05 \pm 0.02 * * *$
\end{tabular}

Data expressed as mean \pm SEM. * Significant at $\mathrm{P}<$ 0.05 ; ** Significant at $\mathrm{P}<0.01$; *** Significant at $\mathrm{P}<$ 0.001 .

\section{Hematological parameters}

There were no significant changes in hematocrit levels between ibuprofen exposed and control rats (Table 6). Red blood cell (RBC) counts in rats that had 14 and 28 days exposure to ibuprofen were not significantly different, compared to control rats, but there was a significant, $\mathrm{P}<0.01$ reduction in $\mathrm{RBC}$ count in rats that received $40 \mathrm{mgkg}^{-1}$ ibuprofen for 7 days (Table 6). Additionally, white blood cell (WBC) counts in rats that had 7 and 14 days exposure to ibuprofen were not significantly different, compared to control rats, but there was significant, $\mathrm{P}<0.01, \mathrm{P}<0.001$ elevation in WBC counts in the rats that were exposed to ibuprofen for 28 days (Table 7). Furthermore, there were no changes in platelet counts in rats that were exposed to ibuprofen for 7 days, but counts obtained in rats that received ibuprofen for 14 and 28 days were significantly, $\mathrm{P}<0.01, \mathrm{P}<0.001$ decreased when compared to control rats. The ibuprofen-induced platelet reduction was dosedependent in the 14 days exposed group, but nondose-dependent in the 28 days exposed group (Table 7).

Table 6: Hematocrit levels and red blood cell (RBC) counts following different dose and time administration of ibuprofen in rats

\begin{tabular}{lcccccc}
\hline Dose & \multicolumn{3}{c}{ Hematocrit $(\%)$} & \multicolumn{3}{c}{ RBC (x 10 $\left.\mu \mathrm{L}^{-1}\right)$} \\
\hline & 7 Days & 14 Days & 28 Days & 7 Days & 14 Days & 28 Days \\
Control & $49.00 \pm 5.48$ & $49.00 \pm 5.48$ & $49.00 \pm 5.48$ & $6.99 \pm 0.53$ & $6.99 \pm 0.53$ & $6.99 \pm 0.53$ \\
& & & & & & \\
$20 \mathrm{mg} / \mathrm{kg}$ & $42.75 \pm 5.56$ & $44.50 \pm 3.70$ & $48.00 \pm 8.91$ & $6.12 \pm 0.41$ & $6.69 \pm 1.18$ & $6.13 \pm 0.71$ \\
$40 \mathrm{mg} / \mathrm{kg}$ & $37.50 \pm 1.29$ & $45.50 \pm 8.39$ & $49.75 \pm 4.92$ & $5.24 \pm 0.18^{*}$ & $6.80 \pm 0.63$ & $5.78 \pm 0.24$
\end{tabular}

Data expressed as mean \pm SEM. * Significant at $\mathrm{P}<0.01$.

Table 7: White blood cell (WBC) and platelet counts following different dose and time administration of ibuprofen in rats

\begin{tabular}{lllllll}
\hline Dose & \multicolumn{5}{c}{ WBC $\left(\times 10^{9} \mu \mathrm{L}^{-1}\right)$} & \multicolumn{3}{l}{ Platelet $\left(\mathrm{x} 10^{3} \mu \mathrm{L}^{-1}\right)$} \\
\hline & 7 Days & 14 Days & 28 Days & 7 Days & 14 Days & 28 Days \\
Control & $4.35 \pm 0.26$ & $4.35 \pm 0.26$ & $4.35 \pm 0.26$ & $445.00 \pm 47.26$ & $445.00 \pm 47.26$ & $445.00 \pm 47.26$ \\
$20 \mathrm{mg} / \mathrm{kg}$ & $4.25 \pm 0.60$ & $4.20 \pm 0.33$ & $5.55 \pm 0.52^{*}$ & $400.00 \pm 16.33$ & $345.00 \pm 37.86^{*}$ & $300.00 \pm 27.08^{* *}$ \\
$40 \mathrm{mg} / \mathrm{kg}$ & $3.93 \pm 0.54$ & $4.43 \pm 0.48$ & $6.23 \pm 0.40^{* *}$ & $420.00 \pm 32.66$ & $312.50 \pm 9.574 * *$ & $259.00 \pm 34.51^{* *}$
\end{tabular}

Data expressed as mean \pm SEM. * Significant at $\mathrm{P}<0.01 ; * *$ Significant at $\mathrm{P}<0.001$. 


\section{Discussion}

Ibuprofen is an effective, cheap, and frequently prescribed nonsteroidal antiinflammatory drug (NSAID). It is an over-thecounter (OTC) drug, and is widely used as an analgesic, antipyretic, and anti-inflammatory drug globally [3,21]. Because of its widespread and frequent usage, regular toxicological evaluation of ibuprofen becomes essential. We report the effects of ibuprofen $\left(20,40 \mathrm{mgkg}^{-1}\right)$ on hepatic, renal, and hematological indices in relation to dose and duration of exposure. The concentrations of ibuprofen used were equivalent to standard therapeutic dose and double of the standard dose of the drug [12].

Serum phosphatase and transaminase levels are generally used in toxicological studies to evaluate hepatic function [22,23]. Elevation in serum levels of alanine transaminase (ALT) and alkaline phosphatase (ALP) by ibuprofen in this study is indicative of cellular injury to the liver. Aspartate aminotransferase (AST) was also increased dose- and time-dependently, although not significantly. As ALT was affected only after 28 days of exposure of the high dose of ibuprofen $\left(40 \mathrm{mgkg}^{-1}\right)$ used in this study, the effect of ibuprofen on liver function strongly correlates positively with the dose and duration of exposure. Accordingly, higher dose levels and/or longer durations of ibuprofen exposure would increase hepatic toxicity, and the elevation of serum AST levels may become significant, as a result of increased leakage of the enzyme from damaged hepatocytes.

NSAIDs are known to alter renal function at high dosages [8,9], partly due to their inhibition of prostaglandin synthesis [4]. However, there is no much information on ibuprofen mediated renal toxicity at clinical dose levels. Urea and creatinine are metabolic waste products that are freely filtered by the glomeruli of the kidneys [24], and their serum concentrations are commonly used as surrogate markers of renal toxicity [25,26]. From our results, ibuprofen would affect renal function as it increased urea and creatinine levels. The result also showed that urea and creatinine were increased by ibuprofen mostly at the high dose $\left(40 \mathrm{mgkg}^{-1}\right)$ and following subchronic exposure. This observation indicates that the renal effects of ibuprofen correlates with its dose and duration of exposure, which is consistent with previous reports on NSAIDs [27]. In addition, the results also show that prolong use of standard dose levels of ibuprofen may alter renal function.

Uric acid is an antioxidant which scavenges reactive oxygen radicals in the blood [28]; ibuprofen-induced reduction of uric acid in this study may alter cellular redox balance and affect biochemical functions. By this observation, ibuprofen may affect antioxidative actions of blood with consequent increase in oxidative stress. This may contribute to some of the toxicological effects of ibuprofen as oxidative stress has been linked to the pathogenesis of most conditions [29]. In addition, since ibuprofen did not affect cholesterol levels, clinical doses of the drug may not affect cholesterol metabolism and may not therefore have direct cardiovascular effects in the rat.

Alteration of hematological function is a common observation in the administration of many therapeutic agents. The present study shows that ibuprofen may not affect hematocrit levels over the dose range and duration of exposure used, but subchronic exposure would increase white blood cell counts. This observation is consistent with the result of a similar study on aquatic animals [30]. Although, NSAIDs are known to have antiplatelet activities [10], the antiplatelet effects of ibuprofen in relation to dose and duration of exposure is not fully established. Our observation of the reduction of platelet counts after 14 and 28 days of ibuprofen exposure, and a non-effect after 7 days of exposure in this study, strongly suggests that the antiplatelet effect of ibuprofen is more important with duration of exposure than dose. Furthermore, the antiplatelet effect of ibuprofen was observed to be dose-dependent during the 14 days treatment, but not dose-dependent during the 28 days treatment. This provides more evidence that the inhibitory effect of ibuprofen on platelet increases more with duration of exposure relative to dose. 


\section{Conclusion}

The implication of this research is that subchronic exposure of standard dose levels of ibuprofen could affect hepatic, renal and hematological functions in the rat; and duration of exposure may increase ibuprofen toxicity relative to dose.

\section{Acknowledgements}

Authors are grateful to laboratory staff of Department of Pharmacology, University of Port Harcourt, Nigeria for providing technical assistance during the study.

\section{References}

1. Green, G. A. Understanding NSAIDs: from aspirin to COX-2, Clinical Cornerstone, 2001, 3(5),50-59. DOI: 10.1016/S1098-3597(01)90069-9

2. Burke, A.; Smyth, E. M.; Fitzgerald, G. A. Analgesic-antipyretic agents; pharmacotherapy of gout, in Goodman \& Gilman's, The pharmacologic basis of therapeutics, 11th ed., Brunton, L. L.; Laxo, J. S.; Parker, K. L., Ed.; McGrawHill: New York, 2006.

3. Bradbury, F. How important is the role of the physician in the correct use of a drug? An observational cohort study in general practice, International Journal of Clinical Practice, Supplement, 2004, (144),27-32. DOI: 10.1111/j.1742-1241.2004.027_e.x

4. Reynolds, E. F. Aspirin and similar analgesic and anti-inflammatory agents, in Martindale: The Extra Pharmacopoeia, 28th Ed., Pharmaceutical Press: London, 1982; pp 234-282.

5. Capone, M. L.; Tacconelli, S.; Di Francesco, L.; Sacchetti, A.; Sciulli, M. G.; Patrignani, P. Pharmacodynamic of cyclooxygenase inhibitors in humans, Prostaglandins \& Other Lipid Mediators, 2007, 82(1-4),85-94.

DOI:10.1016/j.prostaglandins.2006.05.01 $\underline{9}$

6. Traversa, G.; Walker, A. M.; Ippolito, F. M.; Caffari, B., Capurso, L.; Dezi, A.; Koch, M.; Maggini, M.; Alegiani, S. S.; Raschetti, R. Gastroduodenal toxicity of different nonsteroidal antiinflammatory drugs, Epidemiology, 1995, 6(1),49-54. DOI: $\quad 10.1097 / 00001648-199501000-$ $\underline{00010}$

7. Higuchi, K.; Umegaki, E.; Watanabe, T.; Yoda, Y.; Morita, E.; Murano, M.; Tokioka, S.; Arakawa, T. Present status and strategy of NSAIDs-induced small bowel injury, Journal of Gastroenterology, 2009, 44(9),879-88. DOI: 10.1007/s00535-009-0102-2

8. Bennett, W. M.; Henrich, W. L.; Stoff, J. $\mathrm{S}$. The renal effects of nonsteroidal antiinflammatory drugs: Summary and recommendations, American Journal of Kidney Diseases, 1996, 28,S56-S62. DOI:10.1016/S0272-6386(96)90570-3

9. Aprioku, J. S.; Uche, F. I. Renal Effects of non-steroidal antiinflammatory drugs in albino rats, British Journal of Pharmaceutical Research, 2013, 3(3),314-325. DOI: 10.1038/newbio231232a0.6

10. Yokoyama, H.; Ito, N.; Soeda, S.; Ozaki, M.; Suzuki, Y.; Watanabe, M.; Kashiwakura, E.; Kawada, T.; Ikeda, N.; Tokuoka, K.; Kitagawa, Y.; Yamada, Y. Influence of non-steroidal antiinflammatory drugs on antiplatelet effect of aspirin, Journal of Clinical Pharmacy and Therapeutics, 2013, 38(1),12-15. DOI: 10.1111/j.1365-2710.2012.01373.x

11. CCAC (Canadian Council on Animal Care). Guidelines on the care and use of farm animals in research, teaching and testing; CCAC: Ottawa ON, 2009.

12. McQuay, H. J.; Moore, R.A. Doseresponse in direct comparisons of different doses of aspirin, ibuprofen and paracetamol (acetaminophen) in analgesic 
studies, British Journal of Clinical Pharmacology, 2007, 63(3),271-278. DOI: 10.1111/j.1365-2125.2006.02723.x

13. Babson, L. A.; Greeley, S. J.; Coleman, C. M.; Phillips, G. D. Phenolphthalein monophosphate as a substrate for serum alkaline phosphatase, Clinical Chemistry, 1966, 12,482-490. DOI: 10.1007/978-162703-562-0_2

14. Fishman, W. H.; Davidson, H. M. Determination of serum acid phosphatases, in Methods of biochemical analysis, Glick D., Ed.; John Wiley \& Sons: USA, 2006; pp 257-284. DOI: 10.1002/9780470110201.ch7

15. Kaplan, A. The determination of urea, ammonia and urea, in Methods of biochemical analysis, Glick, D. Ed.; California: John Wiley and Sons, 2006. DOI: 10.1002/9780470110355.ch7

16. Tietz, N. W.; Pruden, E. L.; SiggardAnderson, O. Electrolytes, blood gasses and acid base balance, in Textbook of clinical chemistry, Philadelphia: Saunders, 1986.

17. Henry, R. J.; Cannon, D. C.; Winkelman, J. W. Clinical chemistry, principles and techniques, 2nd ed., Harper \& Row: New York, $1974 . \quad$ DOI: 10.1155/S1463924682000066

18. Fossati, P.; Prencipe, L.; Berti, G. Use of 3, 5-dichloro-2-hydroxybenzenesulfonic acid/4-aminophenazone chromogenic system in direct enzymic assay of uric acid in serum and urine, Clinical Chemistry, 1980, 26(2),227-231. DOI: 10.1373/clinchem.2009.139337

19. Roeschlau, P.; Bernt, E.; Gruber, W. J. Enzymatic determination of total cholesterol in serum, Zeitschrift fur klinische Chemie und klinische Biochemie, 1974, 12(5),226. DOI: 10.1021/ed055p63

20. Reitman, S.; Frankel, S. A colorimetric method for the determination of serum glutamic oxaloacetic and glutamic pyruvic transaminase, American Journal of Clinical Pathology, 1957, 28,56-63.
21. Bushra, R.; Aslam, N. An overview of clinical pharmacology of ibuprofen, Oman Medical Journal, 2010, 25(3),1551661. DOI: $10.5001 / \mathrm{omj} .2010 .49$

22. Dufour, D. R.; Lott, J. A.; Nolte, F. S.; Gretch, D. R.; Koff, R. S.; Seeff, L. B. Diagnosis and monitoring of hepatic injury: Recommendations for use of laboratory tests in screening, diagnosis and monitoring, Clinical Chemistry, 2000, 46,2050-2068.

23. Singh, A.; Bhat, T. K.; Sharma, O. P. Clinical biochemistry of hepatotoxicity, Journal of Clinical Toxicology, 2011, S4,001-0019. DOI:10.4172/21610495.S4-001

24. Gaspari, F.; Perico, N.; Matalone, M.; Signorini, O.; Azzollini, N.; Mister, M.; Remuzzi, G. Precision of plasma clearance of iohexol for estimation of GFR in patients with renal disease, Journal of American Society of Nephrology, 1998, 9,310-313.

25. Perrone, R.; Madias, N.; Levy, A. Serum creatinine as an index of renal function: New insights into old concepts, Clinical Chemistry, 1992, 38,1933-1953. DOI: 10.1.1.316.9225

26. Traynor, J.; Geddes, C. C.; Fox, J. G. How to measure renal function in clinical practice, British Medical Journal, 2006, 333,733-737. 10.1136/bmj.38975.390370.7C

DOI:

27. Cox, P. G.; Moons, W. M.; Russel, F. G.; van Ginneken, C. A. Renal handling and effects of $\mathrm{S}(+)$-ibuprofen and $\mathrm{R}(-)-$ ibuprofen in the rat isolated perfused kidney, British Journal of Pharmacology, 1991, 103(2),1542-1546. DOI: 10.1111/j.14765381.1991.tb09824.x

28. Hooper, D. C.; Scott, G. S.; Zborek, A.; Mikheeva, T.; Kean, R. B.; Koprowski, H.; Spitsin, S. V. Uric acid, a peroxynitrite scavenger, inhibits cns inflammation, blood-cns barrier permeability changes, and tissue damage in a mouse model of MS, FASEB Journal, 2000, 14(5),691-698. 
29. Aprioku, J. S. Pharmacology of free radicals and the impact of reactive oxygen species on the testis, Journal of Reproduction \& Infertility, 2013, 14(4),158-172.

30. Saravanan, M.; Devi, K. U.; Malarvizhi, A.; Ramesh, M. Effects of Ibuprofen on hematological, biochemical and enzymological parameters of blood in an Indian major carp, Cirrhinus mrigala, Environmental Toxicology and Pharmacology, 2012, 34(1),14-22. DOI: 10.1016/j.etap.2012.02.005 